\title{
Environmental Indices and Awareness among Residents of Klerksdorp, South Africa (A Cross-Section Study)
}

\author{
Article by O.O Alewi \\ Ph.D in Public Health, Texila American University, South Africa \\ E-mail:physiokay@yahoo.com
}

\begin{abstract}
While increase in urbanization and industrialization has brought many social benefits, including high living standard, economic prosperity, and education. Regrettably, it has also "invited" many material and social problems, diseases, epidemics from poor environmental awareness and behaviour-which all lead invariably to reduce health status of the population; by way of increased air pollution from vehicular congestion, and industrial revolution with their attendant noise pollution, human activities tampering with the eco system and ozone depletion just among others.

The aim of this cross-sectional study is to assess the level of environmental indices awareness and education about the associated diseases that results from poor environmental health practices; among residents of Klerksdorp city in South Africa. A cross sectional study of 100 residents was conducted using a random multistage cluster sampling technique. The target population was drawn from Klerksdorp residents (55\% male and $45 \%$ female) between the ages of 20 and 65 years. Data collection was performed using a well-structured selfadministered, 35-item questionnaire covering environmental awareness on ten indices of environmental factors, and knowledge of adverse health effects associated with them with therapeutic options. Only $13 \%$ on the average have basic environmental health awareness of the indices; leading to a very poor correlation between awareness and associated diseases. $21 \%$ of the respondents have knowledge of adverse health effects associated with environmental hazards. Therapeutic options were fairly demonstrated however; as over 70\% know they have to seek medical attention from hospital if they feel sick. Males score relatively higher than females especially on air pollution and its ill-effects. The study concludes that, there is an urgent need for health promotion in terms of environmental health and indices awareness and health education about healthy environmental practices among the residents survey with a view to enhance health care system.
\end{abstract}

\section{Introduction}

The study of disease is really the study of man and his environment (Park, 2013).Environmental health is one of the core subjects of public health. It is a study of the determinants of the distribution of disease that are exogenous to the correct functioning of human beings. (Rothman \& Greenland, 1998). Indices for environmental health includes, air pollution (from organic fossil burning, car exhausts and industrial wastes), contaminated water, sewage remains, noise pollution, ozone depletion, greenhouse effects, radiation, etc. A number of human activities are the causes of the disruptions of the environment, resulting in ill-health. For example fossil fuel releases a lot of carbon dioxide $\left(\mathrm{CO}_{2}\right)$ into the atmosphere, thereby altering the natural Eco balance of $\mathrm{CO}_{2}$ in the air. Evaluation of environmental health starts with analyzing the awareness of environmental health indices among population of any particular community. This also includes raising awareness and education about environmental health issues across different stakeholders (policy-makers, health practitioners, industry, public, and the media, etc). Investigating potential links between the environment and health (Briggs, 1994).

Environmental health priorities vary significantly from country to country, especially, between developed nations and less developed ones (WHO 1992, 1999). This capstone 
Texila International Journal of Public Health

Volume 5, Issue 1, Mar 2017

project aim is to look at these environmental indices, the level of awareness about them and knowledge about the associated health risks or diseases among the studied population.

For a practical application of environmental health awareness to be meaningful, policy makers or government must integrate the knowledge and wholesome practice of environmental health among its citizenry.

For example, addressing water pollution and sustainability issues is of great importance to environmentalist and public health specialist (Bugyi \& McKeown, 2015). Man need to manage diseases firstly, from paying more than usual attention to its immediate environment.

\section{Background of study area}

Klerksdorp is a city located within the Matlosane Municipality in the Northwest province of South Africa. The municipality comprises the towns of Orkney, Kanana, Stilfontein, Haartbeesfontein, Khuma and Tigane. It is resident to a population of 398,676 (population 2011). Total area of the city is $3,561 \mathrm{~km}^{2}(1,375 \mathrm{sq} \mathrm{mi})$. Klerksdorp racial profiling is made up of Blacks $81 \%$, Whites $14.5 \%$, Coloured 3.5\%, and Indian/Asian $0.8 \%$. This distribution is closely similar to the South African national racial population; hence this cross section study in Klerksdorp gives a good national representation of the level of environmental health awareness among the various racial groups.

\section{Aims of the study}

To evaluate the level of awareness of environmental indices and knowledge about environmental related diseases among Klerksdorp residents.

\section{Significance of the study}

The outcome of this study will contribute to the following:

1. This study will provide useful information about the people's knowledge about environmental health.

2. This study will evaluate the awareness among the residents of the environmental indices.

3. This study will help policy makers and local government authorities about the need for necessary health promotion and awareness practice.

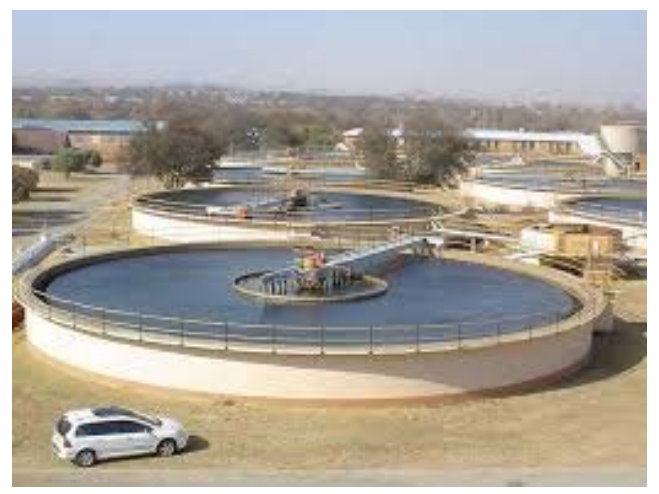

Picture 1. Midvaal water treatment plant in Klerksdorp.

\section{Study limitation}

The sample size was small due to time constraint. A larger representative sample would have yielded a more valid result.

\section{Literature review}

A study by Badr Hel-S, found that the level of environmental worry among high school teacher in Kuwait is significantly positively related to their environmental awareness. (Badr Hel-S, 2003). Such is the significance of this study among the residents of Klerksdorp. Their 
level of awareness is relatively very poor. There has not been a national survey or research in South Africa to assess or evaluate environmental health awareness and its impact on government health system and population behaviours. The available literature is on-going in the city of Cape Town public environment awareness, education and training strategy study, which aim among others is to have an environmentally informed, empowered, and educated skill city. (PEAETS, 2011).

On an international scale, the National Institute of Environmental Health Sciences (NIEHS) under the United States department of health and human services has been involving in innovative research in the area of environmental health with a goal to improve the public health by preventing diseases and disabilities. The institute was able to realise that because environmental health issues crosses national and international boundaries, conducting research studies all across the globe will benefit not only the local population living where the studies are being conducted but all the populations with environmental health problems. (NIEHS, 2015). Most of the studies start with checking the level of environmental health awareness among the people being studied. Effects of environmental health awareness have been observed to be growing among human. (Liu, 2015). More studies are on-going at investigating the exposure effects of chemical, social or physical factors in relation to complex ailments.

Health effects of environmental hazards: The WHO in 2014 releases in its news centres that 7 million premature deaths occur annually due to exposure to air pollution. This is 1 in 8 of total global mortality. (WHO, 2014).Air pollution causes chronic bronchitis, bronchiectasis, emphysema, chronic obstructive pulmonary disease (COPD), lung cancer, skin cancer, etc. (Fowkes, 1992). According to a study conducted in Connecticut, USA, regarding the harmful effects of vehicular air pollution it was found that asthma, COPD, lung cancer, diabetes mellitus, are all exacerbated by motor vehicle pollution exposure.(John, et al, 2006). Radiation exposure from hazardous chemicals and electromagnetic sources reduces the number of fighting blood cells and lymphocytes in the human body, causes central nervous system (CNS) damage, alopecia (baldness), and skin erythema when radiation dose is equal to or exceeds 100mSv. (Kamiya \& Susatani, 2012).

Ozone depletion: Ozone layer protects the earth from the damaging effect of ultraviolet radiation. Man emits chlorofluorocarbons (CFCs) to the atmosphere depleting ozone layer which results in harmful radiations of the sun reflected back to earth. According to skin cancer statistics, in the United Kingdom, ultraviolet radiation remains the major avoidable risk factor for skin cancer. (Cancer research UK, 2012). Ozone layer depletion from unhealthy human practices also increases the amount of ultraviolet radiation B, (UVB) reaching us which causes non-melanoma cancer and malignant melanoma development. (EPA, 2014). Noise pollution from cities and industrial workplaces is associated with hearing loss, ischemic heart disease, hypertension, annoyance and of course sleep disturbance. Evidence link exposure to noise above 60 decibel $(\mathrm{dB})$ in the day time and above $45 \mathrm{~dB}$ at night to an increased evidence of arterial hypertension, mental health disorder, noise induced stress, and sleep disturbances. (SPH, 2011). Noise effects are not only stressful, disturbing and irritating; it also causes after-effects health wise. (Spreng, 2004). Some of the common sources of noise pollution and the amount of rating in decibels are provided in Table1. below.

Table 1.Source credited to NIDCD.

\begin{tabular}{|l|l|}
\hline SOURCES & NOISE RATING IN DECIBEL \\
\hline The humming of a refrigerator & 45 \\
\hline Normal conversation & 60 \\
\hline Noise from heavy traffic & 85 \\
\hline Motorcycles & 95 \\
\hline An MP3 player at max. volume & 105 \\
\hline Sirens & 120 \\
\hline Firecrackers and firearms & 150 \\
\hline
\end{tabular}


Texila International Journal of Public Health

Volume 5, Issue 1, Mar 2017

Hazards also come from poor water treatment, sewage treatment, car pollution, deforestation among others. Comprehensive research into the environmental health becomes more imperative in order to prevent diseases associated with these menace and improve public health practice. According to Gilberto Talero (2004), even with improved public awareness about environmental issue, lack of enough environmental knowledge can still impede achieving a sustainable health for humankind both at local and global levels. Legislation on water safety precautions, banning toxic chemicals in industrial discharge into water sources are also necessary steps of environmental health practice. (Joshua, et al, 2015).

\section{Methodology}

This study is a qualitative research. Qualitative research paradigms offer a perspective in exploring and in understanding human behaviours that comes from a different philosophy than quantitative research methods. (Portney \& Watkins, 2009). In this research, details of the participant's feedback from the questionnaire given were analysed with narrative summaries to express the data.

\section{Study type}

This study is a cross sectional study.

\section{Study setting}

The study was conducted at Klerksdorp city, South Africa.

\section{Study population}

The study population was 100 people, 55 males, and 45 females. These numbers were randomly selected. Sample size calculation done using: The minimum sample size (n) using Slovin's formula: $\mathrm{n}=\mathrm{N} / 1+\mathrm{Ne} 2$

- Where $\mathrm{n}$ is the minimum sample size needed

- e is the level of error that can be tolerated ( 0.05 chance of error)

- $\mathrm{N}$ is the target population $=(140)$

$\mathrm{n}=140 / 1+\left(140 * 0.05^{2}\right)$

$\mathrm{n}=140 / 1+(0.35)$

$\mathrm{n}=103$, approximately 100 .

\section{Data collection and analysis}

Data were collected using a pretested, self-administered questionnaire which contains 35 open and close ended questions in a proportionate sampling of people that make up the city of Klerksdorp. Sampling was drawn from Klerksdorp, Orkney, Kanana, Stilfontein, Haartbeesfontein, Khuma, and Tigane in a cluster fashion. From Klerksdorp, 15 respondents; Orkney, 15; Kanana, 15; Stilfontein, 15; Haartbeesfontein, 15; Khuma, 15; and Tigane, 10. Sampling was done using random multistage cluster sampling technique. Information was collected over a period of 2 weeks travelling between these towns.

Collected data was summarized using frequency tables and bar chart. The analytical approach used was deductive reasoning

\section{Ethical considerations}

The institution (Texila American University) has not sent an ethical clearance certificate yet; however, a bonafide letter will be given in 3 days' time. Written informed consent was sought from the participants. Permission to carry out this study was given by individual consent as studied population provided questionnaire feedback signed an informed consent. 


\section{Results}

\section{Demographics}

A total of 100 respondents took park in this study. Of these numbers, 55 were male, while 45 were female. This is depicted in figure 1 below. From these numbers, eighty five percent $(n=85)$ were university/college graduate, while fifteen percent $(n=15)$ have grade 12 qualification.

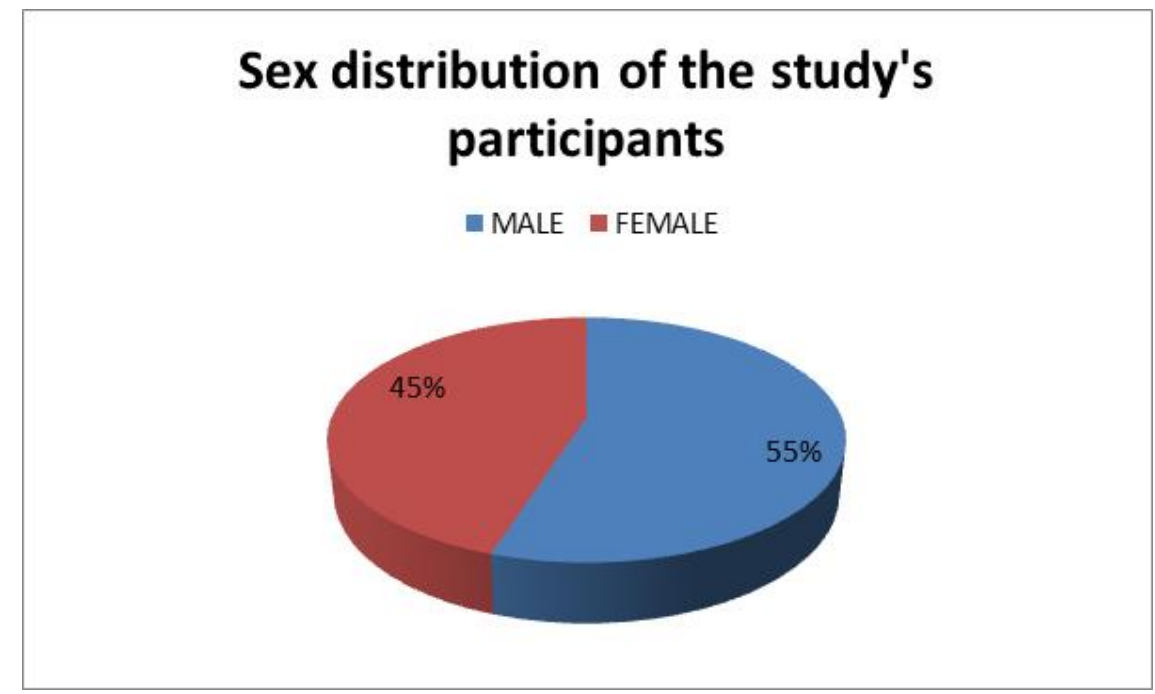

Fig.1

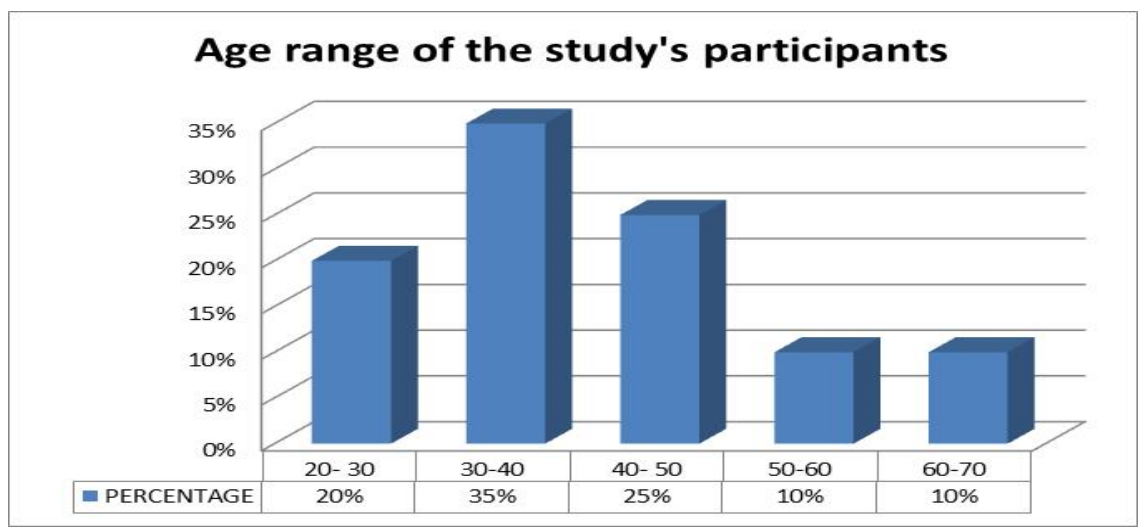

Fig.2

Figure 2 above represent the age distribution of the respondents. Majority were in the age range of 30-40 years (35\%); followed by individuals age $40-50(25 \%) ; 20 \%$ were between the age of 20 and 30 . Old adults (60-70 years) represent $10 \%$, while people between the age of 50 and 60 also represent $10 \%$. 
Texila International Journal of Public Health

Volume 5, Issue 1, Mar 2017

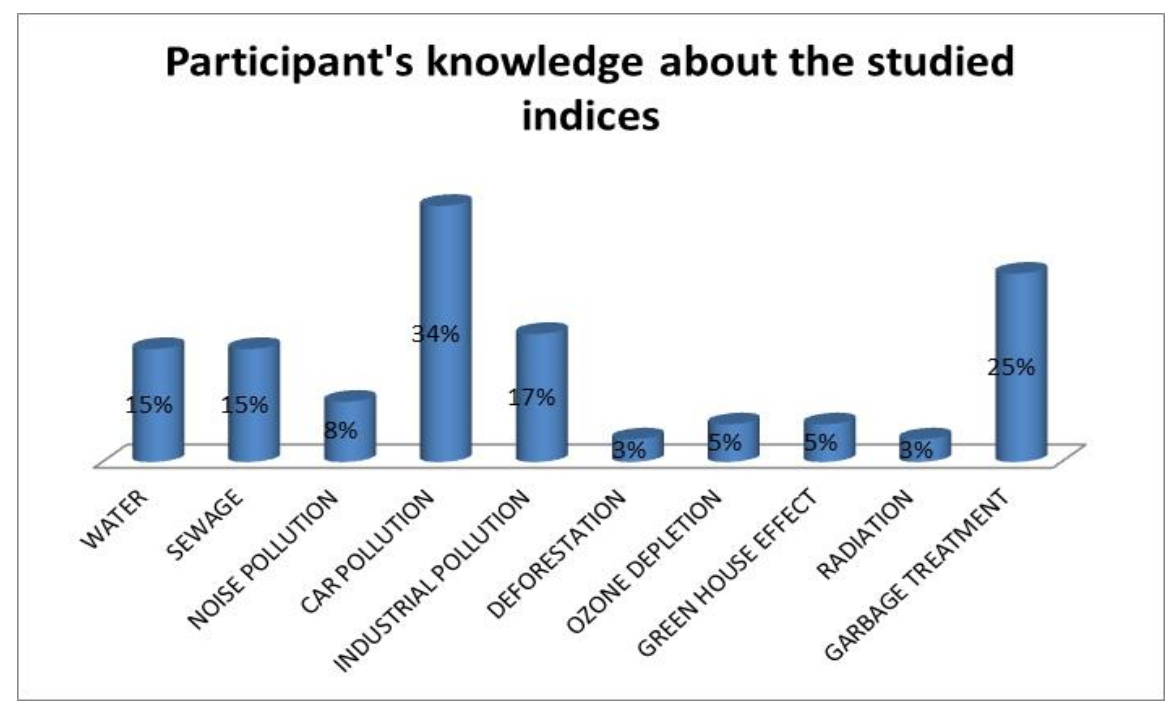

Fig.3

\section{Environmental health awareness}

Figure 3 above summarises the outcome of interest as per the knowledge and awareness about the determinants or indices of the environment. Approximately, one-third, representing (34\%) of the respondents demonstrate good knowledge and awareness about the effects of car pollution on human health. They acknowledge that car pollution especially in commercial cities can cause various lung diseases and negatively impact health. A quarter (25\%) expresses knowledge of hazards associated with poor management or handling or treatment of domestic garbage. They offer practical advice on how to better manage our daily garbage by regular disposal in an airtight polythene plastic and quick removal from homes by the municipal council workers for utmost treatment. This is a common practice in the city of Klerksdorp. Meanwhile, a greater proportion of the respondents (over 90\%) know about garbage disposal, only $25 \%$ demonstrate acceptable knowledge of the impact of not disposing garbage properly can cause to health. They indicate that diseases such as cholera, lung disease, skin infection can result from poor garbage handling at home or at the work places.

\section{Diseases associated with poor environmental indices awareness}

This study only show that the respondents although, few could only attribute ill health to poor water treatment $(15 \%)$, poor sewage treatment $(15 \%)$, car pollution $(34 \%)$, industrial pollution $(17 \%)$ and poor garbage handling $(25 \%)$; most do not know or made aware that other environmental health determinants like noise pollution, deforestation, ozone depletion, greenhouse effects, and radiation has tremendous negative impact on our health. These five indices really need attention in the community in terms of health education. Only four of the respondents acknowledge that putting mobile phones in chest pocket can be dangerous as it emits some amount of electromagnetic radiation dangerous to the body when frequently exposed. 


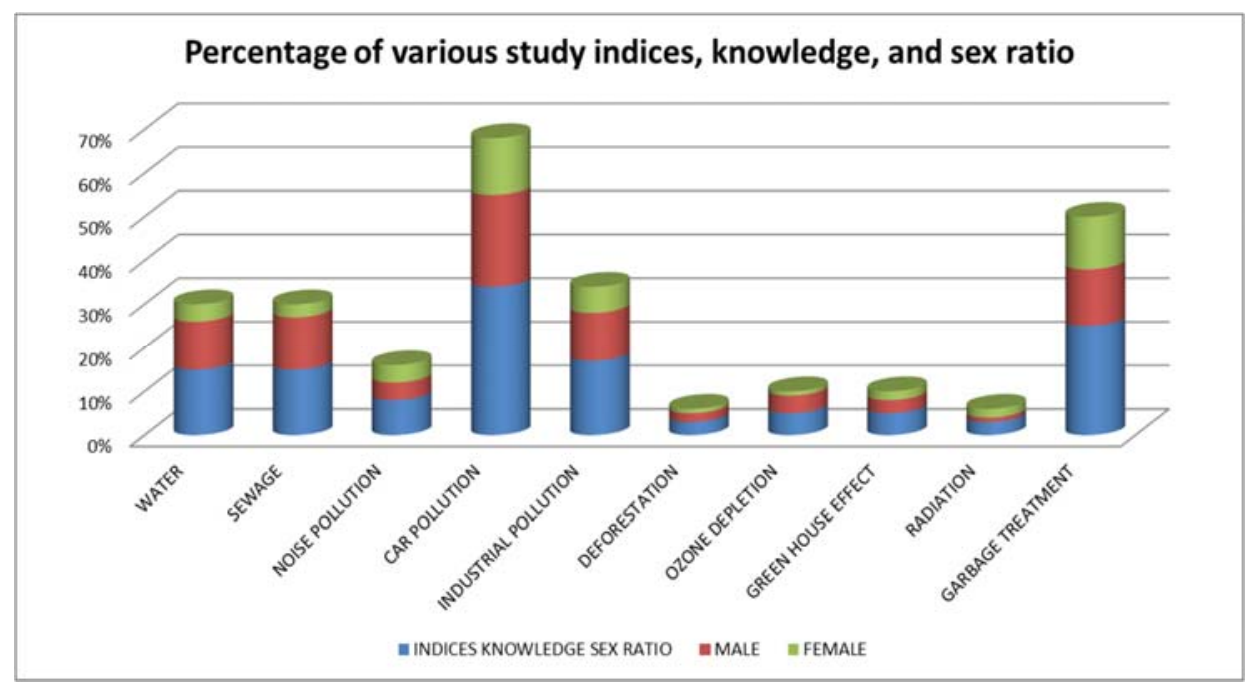

Fig.4

As clearly indicated in figure 4 above, men demonstrate relatively better level of environmental health awareness and education than women. This study, however, did not seek the reason for this difference. The difference could be due to level of education and information; as men appears to be better educated from the data.

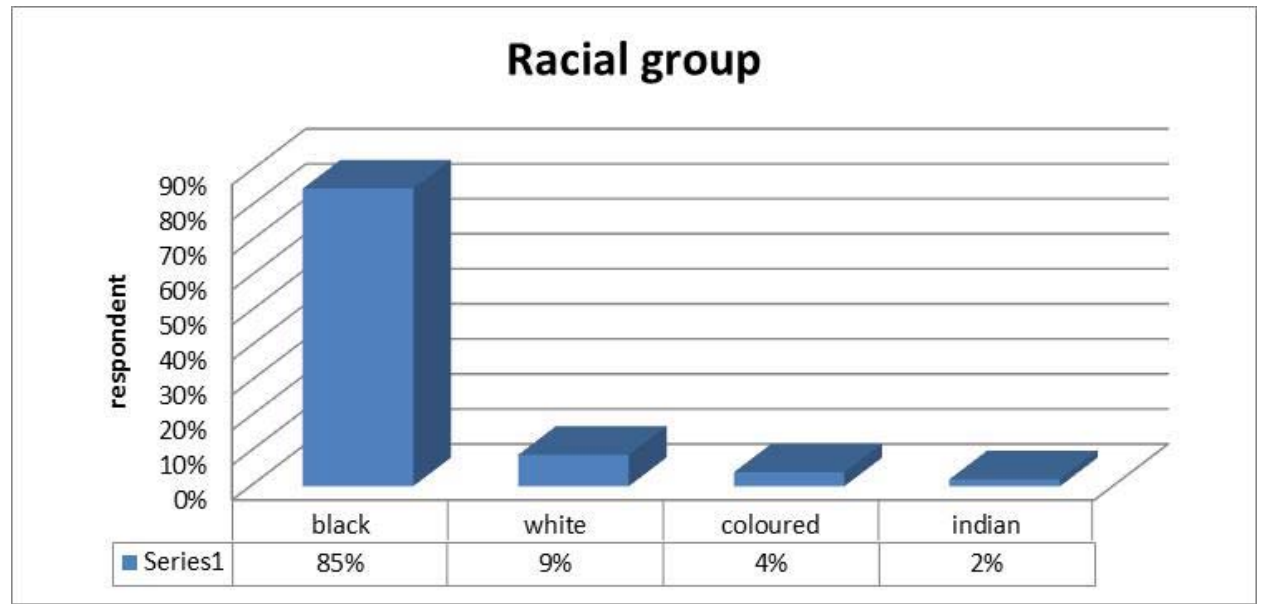

Table. 1

Table 1 indicate the racial proportion of the study. Most of the respondents $(85 \%)$ are black South Africans; white represent 9\%; coloured, 4\%; while Indians only constitute $2 \%$. This ratio is similar to the South African national distribution (Blacks $79.2 \%$, Whites, $8.9 \%$, Coloured 8.9\%, and Indian 2.5\%) (census 2011). 


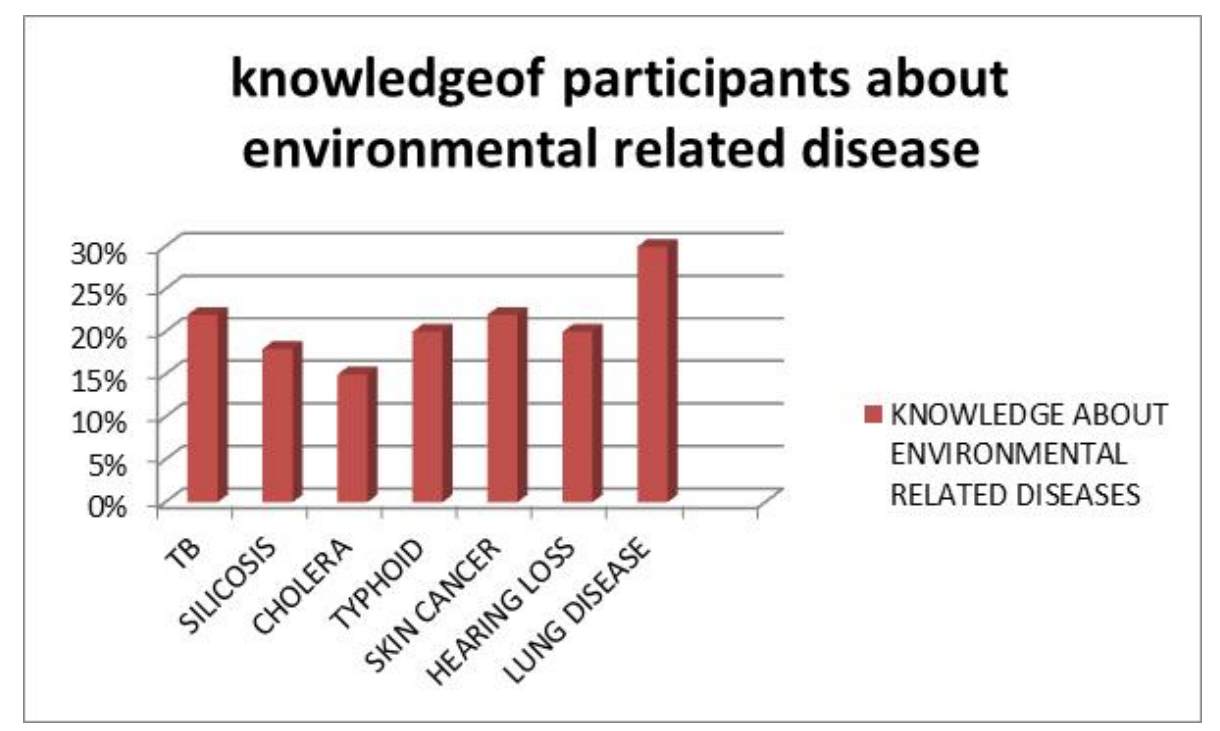

Table. 2.

Knowledge about environmental related diseases was very poor as demonstrated by table 2 above.

\section{Discussion}

This cross sectional study has been able to show that there is an unacceptable level of environmental health indices and awareness among the population studied.85\% of the respondents were college graduates, while $15 \%$ were grade 12 holders. The level of awareness in this study can be said to be adapted from educated ones in the society, yet the outcome was very poor. Fig.2. shows the age distribution as between 20 and 65 years. This is a working age in South Africa, and one would have expected a more knowledge base from this age group; but the result did not correlate. In Fig.3, the indices that received fairly good outcome were car pollution (34\%) and garbage treatment/handling (25\%) at least relatively. Knowledge and awareness in the other 8 indices or determinants were terrible. Many natural or human physical activities are responsible for the release of toxic chemicals into the environment, especially causing air pollution. (Kampa \& Castanas, 2007). Thus, people should be aware of the health implications of these actions. In this study there is also a poor correlation between the adverse effects associated with environmental health and health care consumption. The city should as a matter of urgency, do more in terms of health education, awareness campaigns and health promotion to inform its citizens, especially on environmental health issues. This could be achieved by providing the citizens with health education information via social media, formal and informal training. The results of this study indicate the level of health promotion as very poor. While there has been a study on the effects of environmental knowledge among children (Fisman, 2005), there should be among adults as well. People in the study area are not equipped with adequate knowledge about their health in terms of environmental impact. Many do not even know there is a layer of the atmosphere called ozone, or its relevance to their health. People will continue to degrade the environment through pollution, release of CFCs and unnecessarily exposed themselves to unacceptable decibels, and radiation because of lack of awareness about the effects of these actions on their health. These issues are a global concern, particularly in developing nations such as evident in South Africa from this study. Poor environmental health induced diseases like, cholera, typhoid fever, skin cancer, tuberculosis, silicosis, and lung disorders have killed millions in Africa and this scourge is still on the increase particularly in developing nations of the world. Glasgow et al (1999) observed that there is a need for comprehensive evaluation framework to improve public health and community based interventions. With the local results from this cross sectional study in Klerksdorp district comprehensive evaluation and advocacy for health 
promotion is equally non-negotiable. This study collaborates well with previous two studies done to evaluate the impact of environmental health education and awareness among various populations. First, there was a study in the year 2000 in Malaysia to evaluate the effect of introducing environmental health education and awareness course among student in a pre-post -test design. Post assessments a year later indicate that the level of awareness and knowledge of environmental health has improved. (Amin et al, 2012). In another study, held in Palestinian refugee camp in 2006, a one year study was done to evaluate the impact of environmental health and awareness program among the refugees. After one year on intervention in a pre-post-test design there was also an improvement of environmental health in the camp. (Mourad, 2006). These two studies supported the importance and significance of environmental health education and awareness at improving and promoting environmental health.

\section{Conclusion}

This study clearly demonstrates a low level of awareness about environmental health indices and the diseases associated with them. Hearing loss due to noise pollution referred to as noise-induced hearing loss continues to plaque our society. Environmental health remains one of the core subjects of public health and there is more than urgent need to create the much needed awareness about environmental issues and disease in the context of environmental health practices. With well informed and educated society, we all can positively impact our socio-economic status and environmental health. With the result obtained from this cross section study, is it concluded that there is an unacceptable poor level of environmental health knowledge among the studied population, hence, urgent need for health promotion in this regard.

\section{Recommendations}

There is a need for the South African governments, to include environmental health education in the school curricula, starting from elementary school. Health promotion should receive a boost in terms of educating the public through mass media, social media, formal and informal methods. Benchmarking of the Norwegian environmental education system can be adapted to South Africa local scenario and need. The Norwegian approach was in line with the United Nations Educational Scientific and Cultural Organization (UNESCO) goal. Their ministry of education strategy was that all pupils should receive environmental education. Because the study find out that people could not relate well with governmental intervention in terms of its health economics and management principles, environmental health public awareness should be shaped by economic, social, religion, cultural and educational inputs. It has been shown through similar study that public environmental education and communication are the key tools for reaching out on effective delivery of awareness campaign. (Talero, 2004).

Further studies on environmental health awareness should be conducted with larger sample size in order to add to the reliability and validity of the study. A quantitative research on this subject should also be undertaking with a view to having a systematic review literature on the subject.

\section{References}

[1]. Badr, Hel-S. (2003). Environmental awareness and worry among high school teachers in Kuwait. $J$ Egypt Public Health Assoc, 78(3-4), 319-39. Retrieved from

http://www.ncbi.nlm.nih.gov/pubmed/17265620

[2]. Briggs, D. (1994). Environmental Health Indicators: Framework and methodologies. WHO, Geneva. http://apps.who.int/iris/bitstream/10665/66016/1/WH

[3]. Bastable, B. Susan, Gramet, Pamela, Jacobs, Karen, Sopczyk, L. Deborah. (2011). Health Professional as Educator: Principles of Teaching and Learning. Sandbury. Jones \& Bartlett Learning. 
Texila International Journal of Public Health

Volume 5, Issue 1, Mar 2017

[4]. Cancer Research UK. (2012). Skin cancer diagnosis and treatment statistics. Retrieved from www.cancerresearchuk.org/health-professional/cancer-statistics-by-cancer-type/skin-cancer/diagnosisand-treatm

[5]. City of Matlosane. (2011). Retrieved from https://en.wikipedia.org/wiki/City_of_Matlosana

[6]. Demographics of South Africa. (2011). Retrieved from

https://en.wikipedia.org/wiki/Demographics_of_So

[7]. Fowkes, F.G.R. Maxcy-Rosenau-Last Public Health and Preventive Medicine. (1992). J Epidemiol Community Health, 46(6), 631.

[8]. Glasgow, R.E., Vogt, T.M. \& Boles, S.M.(1999). Evaluating the public health impact of health promotion interventions: the RE-AIM Framework. American Journal of Public Health, 89(9), 13221327. Doi:10.2105/AJPM.89.9.132

[9]. George, Bugyi; Elaine, A. Mckeown. (2015). Impact of water pollution on Human and Environmental Sustainability. Retrieved from

https://www.safaribooksonline.com/library/view/impact-of-water/9781466695597

[10]. Health and Environmental Effects of Ozone Layer Depletion. (2015). Retrieved from https://www.epa.gov/ozone-layer-protection/health-and-environmental effects-ozone-layer-depletion.

[11]. John, Wargo; Linda, Wargo; Nancy, Alderman. (2006). The Harmful Effects of Vehicle Exhaust: A case for policy change. Retrieved from www.ehhi.org/exhaust06.pdf.

[12]. Joshua, Nizel, Halder; M. Nazral, Islam. (2015). Water Pollution and its Impact on the Human Health. Journal of Environment and Human, 2(1).

[13]. Kamiya, K; Sasatani, M. (2012). Effects of radiation exposure on human body. NihonRinsho, 70(3), 367-74. Retrieved from http://www.ncbi.nlm.nih.gov/pubmed/22514910.

[14]. Liu, Chen-Yu. (2015). Epidemiology of Environmental Health. Environmental Epigenetics, Molecular and Integrative Toxicology, DOI 10.1007/978-1-4471-6678-8_2

[15]. Latifah, Amin., Zurina, Mahadi., Rozita, Ibrahim., Mashitoh, Yaacob \& Zubaidah, Nasir. (2012). The Effectiveness of the 'Environment \&Health' course in Increasing Students' Awareness \& Knowledge on Environment Health Issues. Procedia-Social and Behavioral Sciences, 59, 77-84. http://dx.doi.org/10.1016/j.sbspro.2012.09.248

[16]. Lianne, Fisman. (2005). The effects of Local Learning on Environmental Awareness in Children: An Empirical Investigation. The Journal of Environmental Education, 36(3).

[17]. Marilena, Kampa \& Elias, Castanas. (2007). Human health effects of air pollution. Environmental Pollution, 151, 362-367.

[18]. National Institute of Environmental Health Sciences (NIEHS). (2015) Retrieved from http://www.niehs.nih.gov/research

[19]. Portney, L.G. \& Watkins, M.P. (2009). Foundations of Clinical Research: Applications to Practice. Upper Saddle River. Pearson prentice hall.

[20]. Park, K. (2013). Social and Preventive Medicine. Jabalpur. Bhanot

[21]. Public Environmental Awareness, Education and Training Strategy (PEAETS). (2011).

[22]. Rothman \& Greenland. (1998). Modern Epidemiology. Philadelphia. Lippincolt-Raven Publishers.

[23]. Spreng, M. (2004). Noise induced nortunal cortisol secretion and tolerable overhead flights. Noise \& Health Journal, 6(22), 35-47. Retrieved from www.noiseandhealth.org/article.asp?

[24]. South Africa's population. (2015) .Retrieved from

http://www.southafrica.info/about/people/population

[25]. Talero, G. (2004). Environmental Education And Public Awareness. Victoria, Canada. Retrieved from http://worldfish.org/PPA/PDFs/Semi-Annual\%/2011\%/

[26]. Tayser, A.M, Abu, Mourad. (2006). The impact of an environmental health and awareness program on Palestinian refugees of Nuseirat camp: A one-year-after report. JEHR, 5(1). Retrieved from www.cieh.org/JEHR/EH_awareness_palestinian_refugees.html

[27]. WHO. (1992). Our planet, our health. Geneva. WHO

[28]. WHO. (1992). The global health report. Geneva. WHO

[29]. Retrieved from https://www.capetown.gov.za/en/EnvironmentalR 